\title{
Eğitim Fakültesi Öğrencilerinin Akademik Başarıları, Bölümleri, Sınıf Düzeyleri ve Üstbilişsel Farkındalık Düzeyleri Arasındaki İlişkiler
}

\author{
Meryem Özturan Sağırı", Fatih Baş ${ }^{* *}$, Mehmet Bekdemir ${ }^{* * *}$
}

Makale Geliş Tarihi: 27/09/2018

Makale Kabul Tarihi: 03/12/2018

DOI: $10.35675 /$ befdergi.464806

$\ddot{O} z$

Bu araştırmada; öğretmen adaylarının üstbilişsel farkındalık düzeyleri; bu düzeylerin bölüm, sınıf düzeyi ve cinsiyet değişkenlerine göre farklılaşıp farklılaşmadĭ̆ ve üstbilişsel farkındalıklarının akademik başarılarını yordama durumunun incelenmesi amaçlanmıştır. İlişkisel araştırma yöntemi temel alınarak tasarlanan araştırma ilköğretim matematik, sınıf, fen bilgisi ve sosyal bilgiler öğretmenliği programlarından öğrenim gören 764 katılımcr ile gerçekleştirilmiştir. Araştırmanın verileri; katılımcıların demografik bilgileri (öğrenim gördükleri bölüm, sınıf düzeyi, cinsiyet), akademik başarıları (lisans genel başarı ortalaması) ve üstbilişsel farkındalık düzeyleri (Bilişötesi Farkındalık Envanteri puanları) şeklindedir. Verilerin analizinde; betimsel analiz, çok faktörlü ANOVA ve basit doğrusal regresyon testi kullanılmıştır. Analizler sonucunda; katılımcıların büyük bir bölümünün yüksek düzeyde farkındalı̆̆a sahip olduğu belirlenmiştir. Öğrenim görülen bölüm ve bölüm ile sınıf düzeyinin kombinasyonu değişkenlerinin farkındalık üzerinde anlaml bir farklılı oluşturduğu görülmüştür. Ayrıca akademik başarı ve üstbilişsel farkındalık arasında pozitif ve zaylf düzeyde bir ilişsi olduğu, üstbilişsel farkındalığın akademik başarının anlamlı bir yordayıcısı olup toplam varyansın \%1'ini anlamlı olarak açıkladı̆̆ı tespit edilmişsir.

Anahtar Kelimler: Akademik başarı, üstbiliş, üstbilişsel farkındalık

\section{The Relationship between Teacher Candidates' Metacognitive Awareness Levels and Achievements}

\begin{abstract}
In this research, it was aimed to investigate the metacognitive awareness levels of the preservice teachers, whether these levels demonstrate differences or not in terms of the department, class level and gender variables and the case of metacognitive awareness predicting their academic achievements. The research was carried out with 764 participants. Data of this research were the demographic characteristics of participants, academic achievement and their metacognitive awareness levels. As a result of the study, it was determined that a great

\footnotetext{
"Erzincan Binali Yıldırım Üniversitesi, Eğitim Fakültesi, Matematik ve Fen Bilimleri Eğitimi Bölümü, Erzincan, Türkiye, msagirli@ erzincan.edu.tr, ORCID: 0000-0002-5359-3421

${ }^{* *}$ Erzincan Binali Yıldırım Üniversitesi, Eğitim Fakültesi, Matematik ve Fen Bilimleri Eğitimi Bölümü, Erzincan, Türkiye, fbas@erzincan.edu.tr, ORCID: 0000-0002-0035-4912 (i⿱

**** Erzincan Binali Yıldırım Üniversitesi, Eğitim Fakültesi, Matematik ve Fen Bilimleri Eğitimi Bölümü, Erzincan, Türkiye, mbekdemir@erzincan.edu.tr, ORCID: 0000-0003-1884-2938
}

Kaynak Gösterme: Özturan-Sağırlı, M., Baş, F. \& Bekdemir, M. (2020). Eğitim Fakültesi öğrencilerinin akademik başarıları, bölümleri, sınıf düzeyleri ve üstbilişsel farkındalık düzeyleri arasındaki ilişkiler. Bayburt Eğitim Fakültesi Dergisi, 15(29), 1-22. https://doi.org/10.35675/befdergi.464806 
number of the participants had high level of awareness. It was observed that the variables the combination of the studied department and department and class level made a significant difference on awareness. In addition, there was a positive and weak relationship between the academic achievement and metacognitive awareness, the metacognitive awareness was a significant predictor of the academic achievement and explained $1 \%$ of the variance meaningfully.

Keywords: Academic achievement, metacognition, metacognitive awareness

\section{Giriş}

Üstbiliş ilk olarak Flavell (1979) tarafindan "bireylerin bilişsel süreçleri hakkındaki bilgileri ve bu bilişsel süreçleri yönetmek için bu bilgiyi kullanmaları" olarak tanımlanmıştır. Flavell'in ilk üstbiliş tanımlamasında üstbilişle ilgili olarak biliş̧ bilgisi ve biliş düzenlemesi şeklindeki iki bileşen göze çarpmaktadır. Üstbilişin tanımlanmasıyla araştırmacılar üstbilişin bileşenleri üzerine eğilmiş ancak bu bileşenlerinin doğası üzerinde bir türlü hemfikir olamamışlardır (Veenman, 2006). Örneğin Garofalo ve Lester (1985) üstbilişin bilişsel olaylar hakkındaki bilgiinanışlar ve bilişsel aktivitelerin kontrolü-düzenlemesi şeklinde birbiriyle ilgili ancak kesinlikle birbirinden farklı iki parçadan oluştuğuna dikkat çekmiştir. Efklides (2006; 2009)'a göre ise üstbiliş; üstbilişsel bilgi, üstbilişsel deneyimler ve üstbilişsel beceriler olmak üzere üç bileşenden meydana gelmektedir. Her ne kadar araştırmacılar üstbilişin bileşenlerini ve isimlendirmelerini farklı kullansalar da üstbilişsel bilginin üstbilişsel beceriden ayrılması konusunda hemfikir olmuşlardır (Veenman, Van Hout Wolters \& Afflerbach, 2006). Denilebilir ki üstbilişin anlaşllabilmesinde önemli olan nokta; üstbilişsel bilginin ve üsbiliş düzenlemesinin ne olduğunun anlaşılmasıdır. Üstbilişsel bilgi bireylerin, bireylere verilen bilgi, görevlerin ve görevlerde kullanılacak stratejilerin arasındaki etkileşimin doğurduğu durgun bir bilgi birikimini ifade etmektedir. Üstbilişin düzenlenmesi ise bireylerin bir öğrenme sürecinde veya bir görev esnasında süreçlerini planlamak, izlemek, yönetmek veya değerlendirmek adına kullandıkları işlevsel-dinamik bir bilgi türüdür (Van der Stel ve Veenman, 2010; Veenman, 2005). Dolayısıyla tekrar bir üstbiliş tanımı yapılması gerekirse üstbilişin; ne bildiğini bilmenin yanında aynı zamanda bildiğini izleme, kontrol etme ve değerlendirme becerilerini kapsayan biliş bilgisi olduğu söylenebilir.

Zira üstbiliş ile biliş arasında birbiri içine geçmiş dolayısıyla birbirinden ayrılması oldukça zor olan bir etkileşimden söz edilebilir. Bu konuya değinen Veenman (2006) bir analojiyle bu ilişkiyi "bir araç (biliş) ve aracın içindekiler (üstbilişs)" şeklinde anlatmıştır. Ancak bilişten farklı olarak üstbiliş çok çeşitli karar alma süreçlerini, çok farklı izleme ve seçme stratejilerini kullanmayı içerir (Marcus, 2007; Martinez, 2006; Veenman ve diğerleri, 2006; Yang ve Lee, 2013). Dolayısıyla bu bilgi ve becerilerin bir öğrenme görevi esnasında kullanılması öğrenilen şeyin kavranması, anlamlandırılması ve uygulanması açısından oldukça önemlidir (Kroll ve Miller, 1993; Wilson, 1999). Yani üstbiliş yeterince etkili kullanılabilirse öğrenme sürecinde 
etkili bir rol üstlenebilir. Üstbilişin öğrenme ürünlerini tahmin etmedeki anahtar bir değişken olarak rol oynadığını ifade eden çalışmalar mevcuttur (Desoete, 2009; Desoete ve Veenman, 2006). Hatta sayılarla ifade edilecek olursa bir öğrenme görevi esnasında ölçülen üstbiliş öğrenme varyansını \%37'ye kadar açıklayabilmektedir (Veenman ve diğerleri, 2006). Üstbiliş sadece bir ürün olarak öğrenme sonuçlarıyla değil problem çözme becerisi, zekâ akademik başarı gibi değişkenlerle de ilişkilendirilmiştir. Örneğin üstbilişsel farkındalık düzeyindeki değişkenliğgin \%43'ünün kişisel problemleri çözme algısı, düşünme ihtiyacı ve zekâ tarafindan anlamlı katkılarla açıklandığı ifade edilmiştir (Karakelle, 2012). Bütün bu pozitif sonuçlar üstbilişin ölçülmesi yönündeki çalışmalara oldukça hız vermiştir. Bilhassa bireylerin sahip olduğu üstbilişsel farkındalık birçok araştırmanın inceleme konusu olmuştur. Tablo 1'de bu yönde yapılan çalışmalar yer almaktadır.

Tablo 1.

Üstbilişssel Farkındalığın Ölçüldü̈̆̆̈̈ Bazı Çalışmalar

\begin{tabular}{|c|c|c|c|}
\hline$\overline{\text { Yazar }}$ & Y11 & Bölüm & Sinıf Seviyesi \\
\hline Sheorey \& Mokhtari & 2001 & Lise öğrencileri & Belirtilmemiş \\
\hline Bendixen \& Hartley & 2003 & Öğretmen adayları & Belirtilmemiş \\
\hline Vandergrift & 2005 & Lise öğrencileri & Belirtilmemiş \\
\hline Cautinho & 2007 & Üniversite öğrencileri & Belirtilmemiş \\
\hline $\begin{array}{l}\text { Sarwar, Yousuf, Hussain } \\
\& \text { Noreen, }\end{array}$ & 2009 & Eğitim fakültesi & Belirtilmemiş \\
\hline Tok, Özgan \& Döş & 2010 & Eğitim fakültesi & 1. $\sin 1 f$ \\
\hline $\begin{array}{l}\text { Deniz, Küçük, Cansız, } \\
\text { Akgün \& Iş̧leyen }\end{array}$ & 2014 & $\begin{array}{l}\text { OFMA Matematik } \\
\text { öğretmenliği }\end{array}$ & $1,2,3,4$ ve $5 . \sin i f$ \\
\hline Sarpkaya, Arık \& Kaplan & 2011 & $\begin{array}{l}\text { İlköğretim matematik } \\
\text { öğretmenliği }\end{array}$ & 4. $\sin 1 f$ \\
\hline Baykara & 2011 & İngilizce öğretmenliği & $1,2,3$ ve $4 . \sin 1 f$ \\
\hline Belet \& Güven & 2011 & Sinıf öğretmenliği & $1,2,3$, ve 4 . sinif \\
\hline Özsoy \& Günindi & 2011 & $\begin{array}{l}\text { Okulöncesi } \\
\text { öğretmenliği }\end{array}$ & 1,2 ve $4 . \sin 1 f$ \\
\hline Kiremitçi & 2011 & $\begin{array}{l}\text { Beden eğitimi } \\
\text { öğretmenliği }\end{array}$ & Öğretmen adayları \\
\hline Kaya \& Firat & 2011 & Ortaokul & 5 ve 6 . siniflar; \\
\hline Bağçeci, Döş \& Sarıca & 2011 & Ortaokul & 7. siniflar \\
\hline Memnun \& Akkaya & 2012 & $\begin{array}{l}\text { Sinıf-fen ve } \\
\text { matematik } \\
\text { öğretmenliği }\end{array}$ & $1,2,3$, ve 4 . sinif \\
\hline $\begin{array}{l}\text { Baysal, Ayvaz, } \\
\text { Çekirdekçi \& Malbeleği }\end{array}$ & 2013 & Sınıf öğretmenliği & \\
\hline Kana & 2015 & Türkçe öğretmenliği & $1,2,3$ ve 4 . sinif \\
\hline Gül, Köse \& Yılmaz & 2015 & $\begin{array}{l}\text { Ortaöğretim biyoloji } \\
\text { öğretmenliği }\end{array}$ & $2,3,4$. ve $5 . \sin 1 f$ \\
\hline Demir \& Kaya & 2015 & $\begin{array}{l}\text { Türkçe-fen ve sinıf } \\
\text { öğretmenliği }\end{array}$ & 1. ve 4 . $\sin 1 f$ \\
\hline
\end{tabular}


Tablo 1 incelendiğinde yapılan çalışmaların farklı öğrenim seviyelerinde gerçekleştirildiği görülmektedir. Ulusal düzeydeki araştırmacılar üstbilişi çoğunlukla Schraw ve Dennison (1994) tarafindan geliştirilen ve Akın, Abacı ve Çetin (2007) tarafından Türkçe'ye uyarlanan Üstbilişsel Farkındalık Envanteri ile ölçmüşlerdir. Bu ölçeğin haricinde Cartwright-Hatton ve Wells (1997) tarafindan geliştirilen Tosun ve Irak (2008) tarafindan uyarlanan Üstbiliş Ölçeği; Namlu (2004) tarafindan geliştirilen Bilişötesi Öğrenme Stratejileri Ölçeği; Demir (2013) Bilişsel Farkındalık Ölçeği; Altındağ (2008) tarafindan geliștirilen Yürütücü Biliş Becerileri Ölçeği; Coutinho (2007) tarafindan geliştirilen Metacognitive Awareness Inventory (MAI) gibi ölçekler de üstbilişi ölçmek için kullanılan ölçekler arasındadır. Çalışmalarda üstbiliş puanı bu ölçeklerden alınan toplam puan ve/veya ölçeğin alt faktörlerinden alınan toplam puan olarak hesaplanmıştır. Ayrıca Tablo 1'deki çalışmalar üstbilişsel farkındalı̆̆ın incelendiği değişkenler açısından ele alındığında sınıf düzeyi, devam edilen bölüm, cinsiyet, okul türü, yaşanılan bölge, anne-baba eğitim düzeyi gibi değişkenlerin yer aldığı belirlenmiştir. Üstbilişsel farkındalığın cinsiyet değişkeni açısından incelendiği Deniz, Küçük, Cansız, Akgün ve İşleyen, 2014; Gül, Köse ve Y1lmaz, 2015; Özsoy ve Günindi, 2011; Sarpkaya, Arık ve Kaplan, 2011; Sarwar, Yousuf, Hussain \& Noreen, 2009 tarafindan yapılan araştırmalarda cinsiyet anlamlı bir farklılık oluşturmazken (Bağçeci, Döş ve Sarıca, 2011; Baykara, 2011; Belet ve Güven, 2011; Demir, 2013; Kana, 2015) tarafindan yapılan araştırmalarda ise kızların lehine anlamlı bir farklılığın olduğu yönünde tespit edilmiştir. Öğrenim görülen program türü Alkan ve Erdem'in (2014) çalışmasında bilişin bilgisi ve bilişin düzenlenmesi temel boyutlarındaki düzeyleri arasındaki farkın istatistiksel olarak anlamlı farklılaşmazken Memnun ve Akkaya (2012)'nın çalışmasında ise sınıf öğretmenliği öğrencilerinin üstbilişsel farkındalıklarının fen ve matematik öğrencilerine göre daha yüksek olduğu belirlenmiştir. Sınıf düzeyi değişkeni Özsoy ve Günindi'nin (2011) çalışmasında ikinci ve dördüncü sınıflar arasında, dördüncü sınıflar lehine; Memnun ve Akkaya (2012)'nın çalışmasında üçlerin ve dörtlerin birlere ve ikilere göre daha yüksek; Belet ve Güven (2011)'in çalışmasında da farklı alt boyutlarda farklı sınıf seviyelerinin lehine anlamlı fark oluşturduğu görülmüsştür. Bu değişsen Baykara (2011), Gül, Köse ve Yılmaz (2015), Kana (2015) in çalışmasında üstbiliş açısından anlamlı bir fark oluşturmamıştır.

Kaya ve Firat (2011) ve Bağçeci ve diğerleri (2011)'in çalışmalarında 5, 6 ve 7. sınıf öğrencilerinin üstbiliş puanları ile akademik başarıları arasında anlamlı bir ilişki tespit edilmiştir. Bağçeci ve diğerleri (2011) üstbilişsel farkındalığın bütün olarak 7. sınıf öğrencilerinin SBS başarısının \%10'unu açıkladığını, öğrencilerin yılsonu başarısının ise \%12'sini yordamakta olduğunu tespit etmiş̧tir. Akademik başarının bir değişken olarak alındığı üniversite düzeyindeki araştırmalardan Belet ve Güven (2011)'in araştırmasında, sınıf öğretmeni adaylarının bilişüstü stratejilere yönelik alt ölçeklerin tümü ile akademik başarı düzeyleri arasında düşük düzeyde ve pozitif yönde bir iliş̧kinin varlığı belirlenmiştir. Kana'nın (2015) alışmasında ise öğrencilerin öğrenme sürecini düzenlemeleri alt boyutuyla not ortalamaları arasında istatistiksel olarak anlamlı bir farklılığın olduğu sonucuna varılmıştır. Sökmen ve Kılıç (2016) da 
yürütücü biliş puanlarının akademik başarı puanlarını yordama gücünün istatistiksel olarak anlamlı olduğunu bulmuştur. Bendixen ve Hartley (2003), Cautinho (2007), Romainville (1994), Tok, Özgan ve Döş' ün (2010) çalışmalarında da akademik başarı ile üstbilişsel farkındalık arasında anlamlı bir ilişki tespit edilmiştir. Sarpkaya ve diğerleri (2011) tarafından akademik başarı algısı üst düzeyde bulunan matematik öğretmen adaylarının üstbiliş stratejilerini kullanma farkındalıkları orta düzeyde bulunan öğretmen adaylarının üstbiliş stratejilerini kullanma farkındalıklarına göre daha iyi olduğu görülmüştür. Ergül (2004) ve Sarwar ve diğerleri (2009) akademik başarı ve üstbiliş arasında bir ilişkiye rastlamamıştır.

Yukarıda yazılan üstbiliş alanındaki literatür dikkate alındığında üstbilişin birçok değişken açısından çalışıldığı görülmektedir. Ancak yapılan çalışmalarda öğretmen adaylarının üstbilişsel farkındalıklarını öğrenim görülen dört farklı program türü, sınıf düzeyi, cinsiyet ve akademik başarı (AGNO) şeklindeki dört değişken açısından aynı anda ele alındığı çalışmaya rastlanmamıştır. Bu şekilde yapılacak bir araştırmanın öğretmen adaylarının üstbilişsel farkındalıklarına dair daha bütüncül bir resim sunacağı dolayısıyla daha faydalı olacağı düşünülmektedir. Bu araştırmada; öğretmen adaylarının üstbilişsel farkındalık düzeyleri; bu düzeylerin bölüm, sınıf düzeyi ve cinsiyet değişkenlerine göre farklılaşıp farklılaşmadığı ve üstbilişsel farkındalıklarının akademik başarılarını yordama durumunun incelenmesi amaçlanmıştır. $\mathrm{Bu}$ amaç doğrultusunda;

1. Öğretmen adaylarının üstbilişsel farkındalıkları ne düzeydedir?

2. Öğretmen adaylarının üstbilişsel farkındalık düzeyleri bölüm, sınıf düzeyi ve cinsiyet değişkenlerine göre anlamlı olarak farklılaşmakta mıdır?

3. Öğretmen adaylarının üstbilişsel farkındalıkları akademik başarılarını istatistiksel olarak anlamlı yordamakta mıdır?

alt problemlere cevap aranmıştır.

\section{Yöntem}

$\mathrm{Bu}$ araştırma; iki veya daha fazla değişken arasındaki ilişkinin değişkenler üzerinde herhangi bir etki yapılmadan incelenmesi şeklinde tanımlanan (Fraenkel ve Wallen, 2006, s.335) korelasyonel araştırma yöntemi temel alınarak tasarlanmıştır. Bu çalışmada katılımcılara herhangi bir etki yapılmadan sadece onlardan envantere cevap vermeleri istendiğinden bu yöntem tercih edilmiştir.

\section{Katılımcilar}

Çalı̧̧manın örneklemi; 2015-2016 öğretim yılı güz yarıyllında Doğu Anadolu Bölgesi'nde nüfus açısından orta ölçekli bir ilinde yer alan Eğitim Fakültesinin İlköğretim Bölümü, ilköğretim matematik, sınıf, fen bilgisi ve sosyal bilgiler ögretmenliği anabilim dallarında öğrenim görmekte olan toplam 764 katılımcıdan oluşmaktadır. Katılımcıların belirlenmesinde uygun örnekleme yöntemi 
kullanılmıştır. Katılımcıların bölüm, sınıf düzeyi ve cinsiyet değişkenlerine göre dağılımları Tablo 2'de sunulmuştur.

Tablo 2.

Örneklemin Bölüm Sınıf Düzeyi ve Cinsiyet Değişkenlerine Göre Dă̆ılımı

\begin{tabular}{|c|c|c|c|c|c|}
\hline \multirow{2}{*}{ Bölüm } & \multirow{2}{*}{ Sinıf düzeyi } & \multicolumn{2}{|c|}{ Cinsiyet } & \multirow{2}{*}{\multicolumn{2}{|c|}{ Toplam }} \\
\hline & & Kadın & Erkek & & \\
\hline \multirow{4}{*}{$\begin{array}{l}\text { Fen Bilgisi } \\
\text { Öğretmenliği }\end{array}$} & 1. sinif & 17 & 7 & 24 & \multirow{4}{*}{145} \\
\hline & 2. sinif & 36 & 5 & 41 & \\
\hline & 3. sinif & 28 & 14 & 42 & \\
\hline & 4. $\sin 1 f$ & 25 & 13 & 38 & \\
\hline \multirow{4}{*}{$\begin{array}{l}\text { İlköğretim Matematik } \\
\text { Öğretmenliği }\end{array}$} & 1. sinif & 59 & 18 & 77 & \multirow{4}{*}{263} \\
\hline & 2. sinif & 51 & 18 & 69 & \\
\hline & 3. sinif & 37 & 10 & 47 & \\
\hline & 4. $\sin 1 f$ & 43 & 27 & 70 & \\
\hline \multirow{4}{*}{ Sınıf Öğretmenliği } & 1. sinif & 33 & 15 & 48 & \multirow{4}{*}{168} \\
\hline & 2. sinif & 39 & 14 & 53 & \\
\hline & 3. sinif & 29 & 16 & 45 & \\
\hline & 4. $\sin 1 f$ & 10 & 12 & 22 & \\
\hline \multirow{5}{*}{$\begin{array}{l}\text { Sosyal Bilgiler } \\
\text { Öğretmenliği }\end{array}$} & 1. sinif & 33 & 7 & 40 & \multirow{5}{*}{175} \\
\hline & 2. sinif & 15 & 21 & 36 & \\
\hline & 3. sinif & 37 & 22 & 59 & \\
\hline & 4. $\sin 1 f$ & 21 & 19 & 40 & \\
\hline & Toplam & 513 & 238 & 751 & \\
\hline
\end{tabular}

Tablo 2'de sunulduğu üzere ilköğretim matematik öğretmenliği hariç diğer anabilim dallarındaki katılımcı sayıları hemen hemen birbirine eşittir. Sınıf düzeyinde ise katılımcı sayıları hemen hemen eşittir. Cinsiyet açısından kadın katılımcıların sayısı erkeklerden yüksektir.

\section{Veri Toplama Araçları ve Verilerin Toplanması}

Araştırmada katılımcıların demografik özellikleri (öğrenim gördükleri bölüm, sınıf düzeyi, cinsiyet), akademik başarıları (lisans genel başarı ortalaması) ve üstbilişsel farkındalık düzeyleri şeklinde üç farklı veri toplanmıştır.

Katılımcıların demografik özelliklerini ve akademik başarını belirlemek için araştırmacılar tarafından bir form hazırlanmıştır. Katılımcıların üstbilişsel farkındalıklarına ait veriler ise Schraw ve Dennison (1994) tarafından geliştirmiş ve Akın ve diğerleri (2007) tarafından Türkçe'ye çevrilmiş ve geçerlik-güvenirlik çalışmaları yapılmış olan 5'li Likert tipindeki "Bilişötesi Farkındalık Envanteri (Metacognitive Awareness Inventory (MAI))" kullanılarak toplanmıştır. MAI envanteri; açıklayıcı bilgi, işlemsel bilgi, durumsal bilgi, planlama, izleme, değerlendirme, hata ayıklama ve bilgi yönetme şeklinde sekiz alt boyut altında toplam 52 maddeden oluşmaktadır. Bu envanterden alınacak en düşük puan 52 iken en yüksek 
puan 260’tır. Alınacak düşük puan üstbiliş farkındalığın düşüklüğünü, yüksek puan ise üstbiliş farkındalığının yüksekliğini göstermektedir. Envanterin tümü için Cronbach Alfa güvenirlik katsayısı Schraw ve Dennison (1994) tarafindan =.95, Akın ve diğerleri (2007) tarafindan yine $=.95$ ve bu araştırmada da $=.938$ olarak hesaplanmıştır. $\mathrm{Bu}$ değer .70'in üzerinde olduğundan ölçekten elde edilen veriler güvenilir ve analizlerin raporlaştırılması için uygun (Lance, Butts \& Michels, 2006) olarak değerlendirilmiştir.

Hazırlanan form ve Bilişötesi Farkındalık Envanteri tekbir ölçme aracında birleştirilmiş ve gerekli izinler alınarak katılımcılara sınıf ortamında doldurmaları üzere sunulmuştur. Ölçümlerin bağımsızlığı varsayımı sağlayabilmek adına öğrencilerin birbirlerini etkilemeleri engellenmiştir. Veriler bilgisayara aktarılarak analize hazır hale getirilmiştir.

\section{Verilerin Analizi}

Elde edilen verilerin alt problemler bazında analizi yapılmış olup birinci alt problem kapsamında katılımcıların üstbilişsel farkındalık düzeylerini ortaya koyabilmek amacıyla düşük, orta ve yüksek şeklinde üç düzey belirlenmiştir. Verilerin bu düzeylere dağılımını sağlayabilmek beşli Likert tipindeki ölçek her bir maddeye ilişkin aralık 1-2.333 arası düşük, 2.334-3,666 arası orta ve 3.667-5 arası yüksek şeklinde üç alt aralığa ayrılmıştır. Bu sinırlar ölçekteki madde sayısı olan 52 ile çarpılarak katılımcılar ölçekten aldığı toplam puana göre "52-121.316; düşük", “121.368-190.632; orta” ve "190.684-260; yüksek şeklinde sınıflandırılmıştır. Elde edilen bulgular grafikler kullanılarak sunulmuştur.

Demografik özellikler temel alınarak üstbilişsel farkındalık düzeyinin değişiminin ele alındığı ikinci alt problemlere ilişkin analizlere karar verirken öncelikle verilerin normal dağılıma uygunluğu incelenmiştir. Skewness ve Kurtosis değerlerinin temel alındığı bu süreçte envanterin alt boyutlarındaki ve geneli ve değerleri Tablo 3'te sunulmuştur.

Tablo 3.

Verilerin Dă̆llımına İlişkin Çarpıklık ve Basıklık Değerleri

\begin{tabular}{lll}
\hline & Çarpıklık & Basıklık \\
\hline Açılayıcı bilgi & -.719 & 1.730 \\
Prosedural bilgi & -.522 & .667 \\
Durumsal bilgi & -.454 & .092 \\
Planlama & -.512 & .710 \\
İzleme & -.506 & .721 \\
Değerlendirme & -.493 & .288 \\
Hata ayıklama & -.945 & 1.678 \\
Bilgiyi yönetme & -.571 & .821 \\
\hline Genel & -.628 & 1.516 \\
\hline
\end{tabular}


Tablo 3'te sunulduğu üzere verilerin dağılımı incelendiğinde envanterin alt boyutları ve tamamına ait verilerin dağılımına ilişkin Skewness ve Kurtosis değerleri +2 ie -2 arasında olmasından hareketle ilgili dağılımların normal olduğu (DeCarlo, 1997) kabul edilmiştir. Ayrıca Q-Q plot grafikleri incelendiğinde tüm alt boyutlar ve toplam puana göre tüm değerler köşegen üzerinde veya çok yakınında toplandığından verilerin normal dağıldığ 1 kabul edebilir.

Alt problemlerle ilgili olarak katılımcılardan sınıf düzeyi ve cinsiyet şeklinde üç farklı demografik bilgi toplanmıştır. Bu değişkenlerin üstbilişsel farkındalık üzerine ayrı ayrı etkilerinin yanında kombinasyonlarının etkilerinin de olabileceği düşüncesinden hareketle buna imkân tanıyan çok faktörlü ANOVA testi kullanılmıştır. Analiz sonucunda bulunan farklılıkların kaynaklarının belirlenmesi amacıyla varyansların homojen olması ve gruplardaki katılımcı sayılarının eşit olmaması durumunda kullanılan Scheffe testi (Kayri, 2009) tercih edilmiştir.

Çalışmanın üçüncü alt problemi olan problem çözmeye yönelik inançları ve problem çözmeye yönelik tutumları üstbiliş farkındalığın anlamlı yordayıcısı olup olmadığını analiz etmek için basit doğrusal regresyon testi kullanılmıştır.

\section{Bulgular}

Bulgular alt problemler doğrultusunda sırasıyla aşağıda sunulmuştur.

\section{“Öğretmen Adaylarının Üstbilişsel Farkındalıkları Ne Düzeydedir?” Şeklindeki Birinci Alt Probleme İlişkin Bulgular}

$\mathrm{Bu}$ alt probleme cevap bulabilmek amaciyla katılımcıların envanterden aldıkları toplam puanlar; "52-121.316; düşük", "121.368-190.632; orta" ve "190.684-260; yüksek" şeklindeki sınıflama temel alınarak betimsel olarak analiz edilmiştir. Elde edilen bulgular Şekil 1'de sunulmuştur.

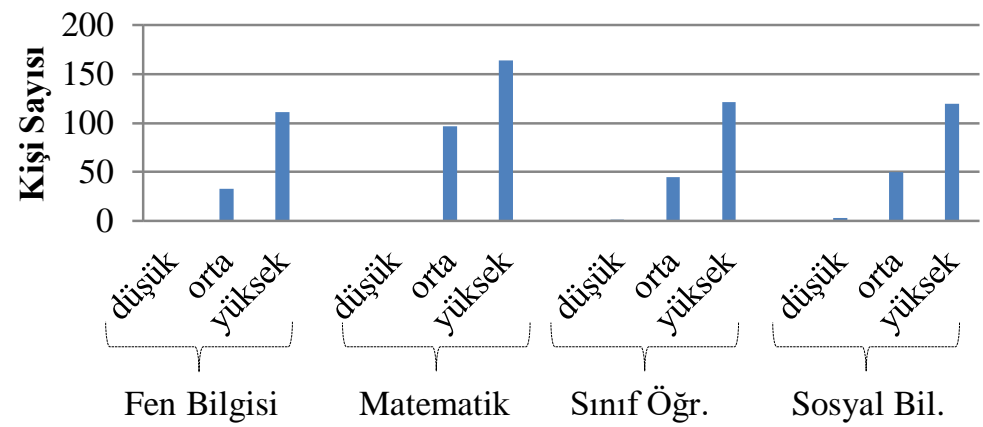




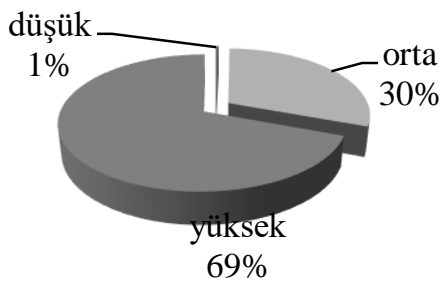

Genel Dağılım

Şekil 1. Katılımcıların üstbilişsel farkındalık düzeylerinin dağılımı

Şekil 1'de sunulduğu üzere fen bilgisi öğretmen adayların \%77'si $(n=111)$ ilköğretim matematik öğretmen adaylarının \%63'ü (n=164), sınıf öğretmen adaylarının \%72'si (n=121) ve sosyal bilgiler öğretmen adaylarının \%69'u (n=120) yüksek düzeyde üstbilişsel farkındalığa sahiptir. Düşük düzeyde farkındalık oranı ise sosyal bilgiler öğretmen adaylarında $\% 2(n=3)$ ve sınıf öğretmen adaylarında $\% 1$ $(n=1)$ şeklindedir. Fen bilgisi ve ilköğretim matematik öğretmen adayları arasında düşük düzeyde farkındalığa sahip katılımcı bulunmamaktadır. Genel olarak incelendiğinde katılımcıların \%69'u yüksek, \%30’u orta ve \%1'i de düşük düzeyde farkındalığa sahiptir.

\section{“Öğretmen Adaylarının Üstbilişsel Farkındalık Düzeyleri Bölüm, Sınıf Düzeyi ve Cinsiyet Değişkenlerine Göre Farklılaşmakta Mıdır?’ Şeklindeki İkinci Alt Probleme İlişkin Bulgular}

$\mathrm{Bu}$ alt probleme cevap bulabilmek amaciyla katılımcıların envanterden aldıkları puanlar bölüm, sınıf düzeyi, cinsiyet ve bu değişkenlerin faklı kombinasyonları temel alınarak faktöriyel ANOVA testi ile analiz edilmiştir. Verilere ilişkin betimsel istatistikler Tablo 4'te sunulmuştur.

Tablo 4.

Üstbilişsel Farkındalık Puanlarının Bölüm, Sınıf Düzeyi ve Cinsiyet Değişkenlerine Göre Betimsel İstatistikler

\begin{tabular}{|c|c|c|c|c|c|c|c|c|c|c|c|}
\hline Bölüm & $\begin{array}{l}S i n \\
D \dot{u}\end{array}$ & $\begin{array}{l}\text { Cins } \\
\text { yet }\end{array}$ & $\bar{x}$ & $s s$ & $n$ & Bölüm & $\begin{array}{l}\text { Sin. } \\
\text { Düz. }\end{array}$ & $\begin{array}{l}\text { Cins } \\
\text { yet }\end{array}$ & $\bar{x}$ & ss & $n$ \\
\hline \multirow{9}{*}{ 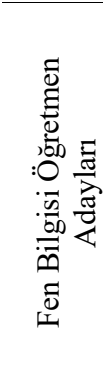 } & \multirow{3}{*}{1} & 1 & 199.00 & 22.27 & 17 & \multirow{9}{*}{ 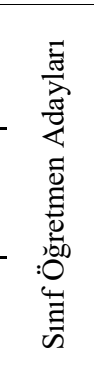 } & \multirow{3}{*}{1} & 1 & 205.81 & 21.61 & 32 \\
\hline & & 2 & 200.14 & 21.25 & 7 & & & 2 & 188.53 & 29.29 & 15 \\
\hline & & $\mathrm{T}$. & 199.33 & 21.52 & 24 & & & $\mathrm{~T}$. & 200.30 & 25.34 & 47 \\
\hline & \multirow{3}{*}{2} & 1 & 207.33 & 17.12 & 36 & & \multirow{3}{*}{2} & 1 & 200.69 & 26.09 & 39 \\
\hline & & 2 & 201.40 & 34.07 & 5 & & & 2 & 206.36 & 25.63 & 14 \\
\hline & & $\mathrm{T}$. & 206.61 & 19.40 & 41 & & & $\mathrm{~T}$. & 202.19 & 25.85 & 53 \\
\hline & \multirow{3}{*}{3} & 1 & 206.29 & 23.49 & 28 & & \multirow{3}{*}{3} & 1 & 212.07 & 18.52 & 29 \\
\hline & & 2 & 206.29 & 16.30 & 14 & & & 2 & 217.50 & 20.14 & 16 \\
\hline & & T. & 206.29 & 21.16 & 42 & & & T. & 214.00 & 19.06 & 45 \\
\hline
\end{tabular}




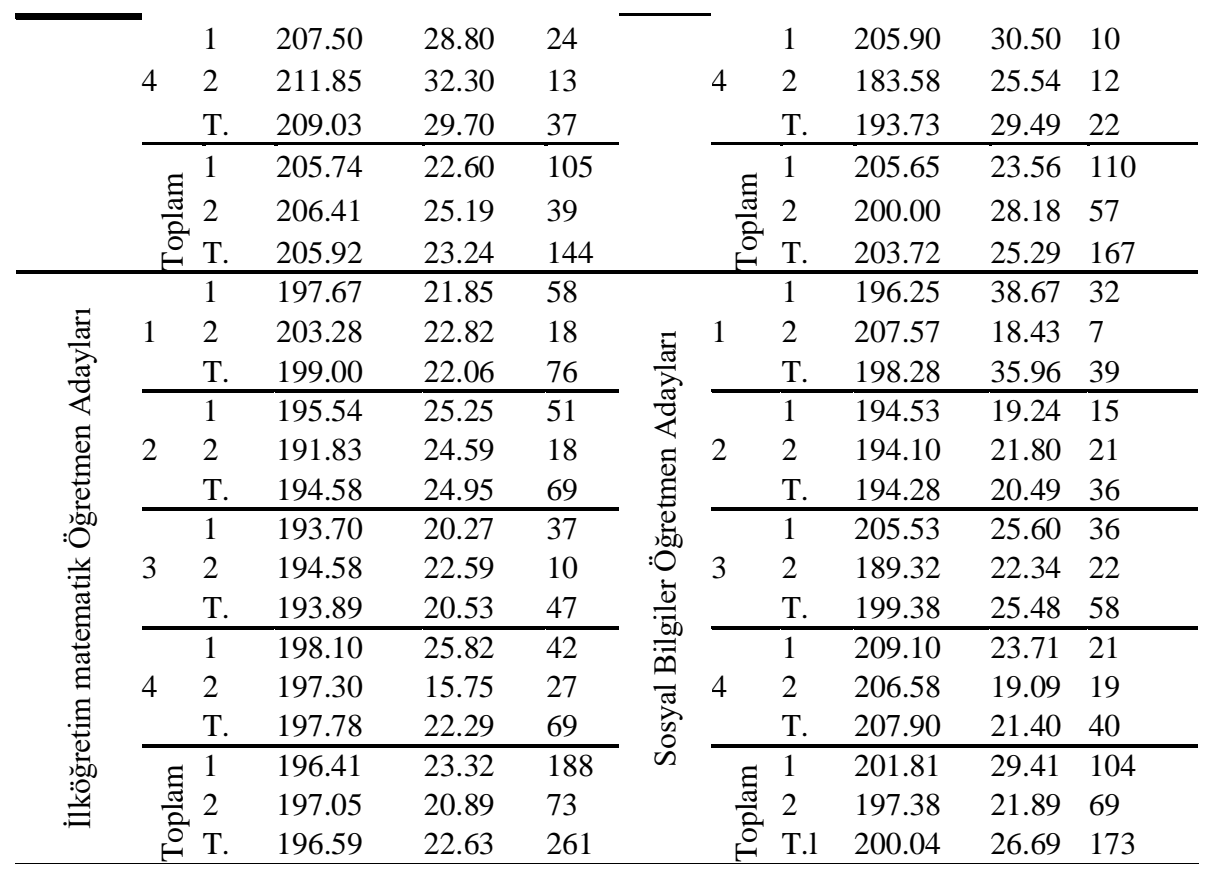

Tablo 4'te sunulduğu üzere veriler genel olarak ele alındığında katılımcıların farkındalık puanları cinsiyet açısından ele alındığında ortalama ve standart sapma değerleri kadınlar için $\bar{x}=201.46-$ ss=24.88 iken erkekler için $\bar{x}=199.39$ - ss=23.89 şeklindedir. Sınıf düzeyleri açısından ortalama ve standart sapma değerleri birinci sinıfta $\bar{x}=199.22$ - ss=26.09; ikinci sinıfta $\bar{x}=199.03$ - ss=23.77 üçüncü sinıfta $\bar{x}=202.97-$ ss=23.03 ve dördüncü sinıfta ise $\bar{x}=202.14-$ ss=25.39'dır. Bölümler açısından ele alındığında ortalama ve standart sapma değerleri sırasıyla fen bilgisi öğretmenliği anabilim dalında öğrenim görmekte olan katılımcıların için $\bar{x}=205.92$ ss:23.24; ilköğretim matematik için $\bar{x}=196.59$ - ss=22.63; sınıf öğretmenliği için $\overline{\mathrm{x}}=203.72-\mathrm{ss}=25.29$ ve sosyal bilgiler öğretmenliği için $\overline{\mathrm{x}}=200.04-\mathrm{ss}=26.69$ şeklindedir. $\mathrm{Bu}$ üç temel değişkene göre farklılıklar söz konusu iken Tablo 3 'te sunulduğu üzere bu üç değişkenin farklı kombinasyonlarından oluşan grupların ortalamaları da farklılık göstermektedir.

İlgili farklılıkların anlamlı olup olmadığını belirlemek için yapılan Çok faktörlü ANOVA testi sonuçları Tablo 5'te sunulmuştur. 
Tablo 5 .

Çok Faktörlü ANOVA Testi Sonuçları

\begin{tabular}{lllll}
\hline Değişken & df & $\mathrm{F}$ & $\eta 2$ & $\mathrm{p}$ \\
\hline Bölüm & 3 & 3.202 & .013 & .023 \\
Sinıfdüzeyi & 3 & .969 & .004 & .407 \\
Cinsiyet & 1 & 1.084 & .002 & .298 \\
Bölüm * sinıfdüzeyi & 9 & 2.531 & .031 & .007 \\
Bölüm * cinsiyet & 3 & .729 & .003 & .535 \\
Sınıfdüzeyi * cinsiyet & 3 & .313 & .001 & .816 \\
Bölüm * sinıfdüzeyi * cinsiyet & 9 & 1.834 & .023 & .059 \\
Eror & 713 & & & \\
\hline
\end{tabular}

Tablo 5'te sunulduğu üzere katılımcıların üstbilişsel farkındalıkları bölüm $(\mathrm{F}(3,713)=$

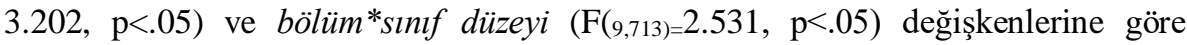
anlamlı olarak değişmektedir. Fakat katılımcıların üstbilişsel farkındalıkları, sınıf düzeyi $(\mathrm{F}(3,713)=.969, \mathrm{p}>.05)$, cinsiyet $(\mathrm{F}(1,713)=1.084, \mathrm{p}>05)$, bölüm*cinsiyet $(\mathrm{F}(3,713)=$ $.729, \mathrm{p}>.05)$, sinıf düzeyi ${ }^{*}$ cinsiyet $(\mathrm{F}(3,713)=.313, \mathrm{p}<.05)$ ve bölüm ${ }^{*}$ sınıf düzeyi ${ }^{*}$ cinsiyet $(\mathrm{F}(9,713)=1.834, \mathrm{p}>05)$ değişkenlerine göre anlamlı farklılık göstermemektedir .

Üstbilişsel farkındalık üzerinde bölüm değişkenine göre oluşan farklılığın kaynağını belirlemek amacıyla yapılan Scheffe testi sonuçları Tablo 6'da sunulmuştur.

Tablo 6.

Bölüm Değişkenine İlişkin Scheffe Testi Sonuçları

\begin{tabular}{llllll}
\hline & & & & \multicolumn{2}{c}{$\% 95$ Güven Aralığı } \\
\cline { 5 - 6 } & & & & Bölüm \\
Bölüm (I) & $\begin{array}{l}\text { Ortalama } \\
\text { fark1 (I-J) }\end{array}$ & $\begin{array}{l}\text { Std. } \\
\text { Hata }\end{array}$ & Alt Sınır & $\begin{array}{l}\text { Üst } \\
\text { Sınır }\end{array}$ \\
\hline Fen Bilgisi & $\mathrm{b}$ & $9.335^{*}$ & 2.527 & 2.256 & 16.415 \\
Öğretmenliği (a) & $\mathrm{c}$ & 2.199 & 2.768 & -5.557 & 9.955 \\
& $\mathrm{~d}$ & 5.883 & 2.746 & -1.810 & 13.577 \\
İlköğretim Matematik & $\mathrm{a}$ & $-9.335^{*}$ & 2.527 & -16.415 & -2.256 \\
Öğretmenliği (b) & $\mathrm{c}$ & $-7.136^{*}$ & 2.412 & -13.895 & -0.378 \\
& $\mathrm{~d}$ & -3.452 & 2.386 & -10.139 & 3.234 \\
Sınıf Öğgretmenliği (c) & $\mathrm{a}$ & -2.199 & 2.768 & -9.955 & 5.557 \\
& $\mathrm{~b}$ & $7.136^{*}$ & 2.412 & 0.378 & 13.895 \\
& $\mathrm{~d}$ & 3.684 & 2.641 & -3.715 & 11.083 \\
Sosyal Bilgiler & $\mathrm{a}$ & -5.883 & 2.746 & -13.577 & 1.810 \\
Öğretmenliği (d) & $\mathrm{b}$ & 3.452 & 2.386 & -3.234 & 10.139 \\
& $\mathrm{c}$ & -3.684 & 2.641 & -11.083 & 3.715 \\
\hline
\end{tabular}

$* \mathrm{p}<.05$

Tablo 6'da sunulduğu üzere ilköğretim matematik anabilim dalı öğretmen adaylarının üstbilişsel farkındalıkları fen bilgisi $(p<.05)$ ve sınıf öğretmenliği $(p<.05)$ 
anabilim dallarındaki öğretmen adaylarının üstbilişsel farkındalıklarından anlamlı olarak farklıdır. Buna göre hem fen bilgisi hem de sınıf öğretmen adaylarının üstbilişsel farkındalıkları ilköğretim matematik öğretmenliği öğretmen adaylarının üstbilişssel farkındalıklarından anlamlı olarak yüksektir. Diğer anabilim dallarının arasında anlamlı fark bulunamamıştır.

Üstbilişsel farkındalık üzerinde bölüm*sınıf düzeyi değişkenine göre oluşan farklılığın kaynağını belirlemek için üstbilişsel farkındalığın değişim grafiği oluşturulmuş ve Şekil 2 de gösterilmiştir.

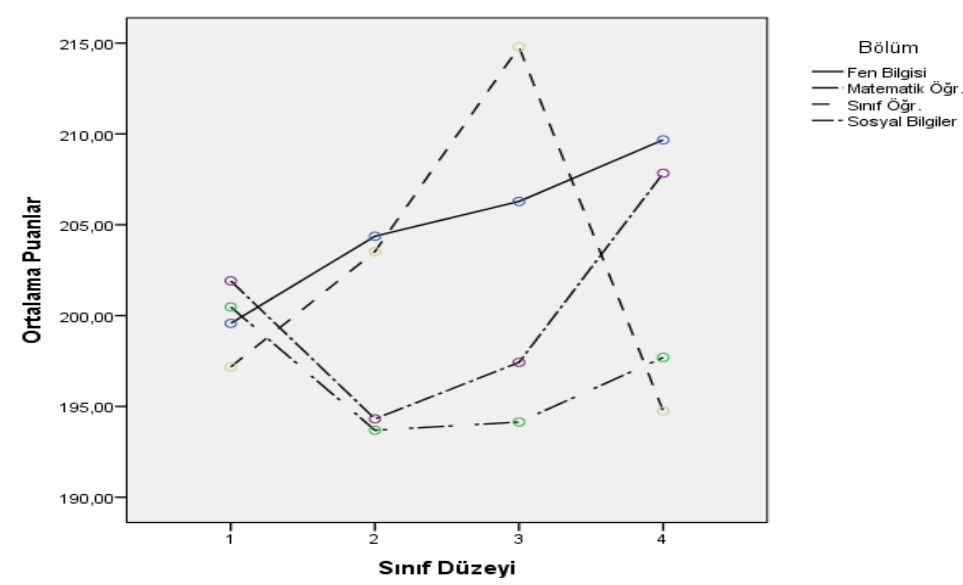

Şekil 2. Bölüm *sınıf değişkenine göre üstbiliş farkındalığının değişim grafiği

Şekil 2'ye göre bölümlerin birinci sınıflar için tüm anabilim dalındaki öğretmen adaylarının üstbiliş farkındalıkları arasındaki fark anlamlı değildir ( $p>.05$ ). İkinci sınıfta fen bilgisi öğretmenliği ve sınıf öğretmenliği anabilim dalı öğretmen adaylarının üstbiliş farkındalıkları ilköğretim matematik öğretmenliği ve sosyal bilgiler öğretmenliği anabilim dalı öğretmen adaylarının üstbiliş farkındalıklarında anlamlı olarak daha yüksektir (p<.05). Diğer anabilim dalındaki öğretmen adaylarının üstbiliş farkındalıkları arasındaki fark anlamlı değildir ( $p>.05)$. Üçüncü sınıfta ise sınıf öğretmenliği anabilim dalı öğretmen adaylarının üstbiliş farkındalıkları diğer anabilim dalı öğretmen adaylarının üstbiliş farkındalıklarından anlamlı olarak daha yüksektir. Yine fen bilgisi anabilim dalı öğretmen adaylarının üstbiliş farkındalıkları sosyal bilgiler ve ilköğretim matematik anabilim dalı öğretmen adaylarının üstbiliş farkındalıklarından anlamlı olarak yüksektir. Diğer anabilim dalındaki öğretmen adaylarının üstbiliş farkındalıkları arasındaki fark anlamlı değildir ( $>>05)$. Son olarak dördüncü sinıfta fen bilgisi öğretmenliği ve sosyal bilgiler öğretmenliği anabilim dalı öğretmen adaylarının üstbiliş farkındalıkları anlamlı olarak ilköğretim matematik öğretmenliği ve sınıf öğretmenliği anabilim dalı öğretmen adaylarının üstbiliş 
farkındalıkları anlamlı olarak daha yüksektir $(p<.05)$. Diğer anabilim dalındaki öğretmen adaylarının üstbiliş farkındalıkları arasındaki fark anlamlı değildir ( $p>.05)$

“Öğretmen Adaylarının Akademik Başarıları Üstbilişsel Farkındalık Düzeyleri Tarafından Yordanmakta Mıdır?" Şeklindeki Üçüncü Alt Probleme İlişkin Bulgular

Üstbilişsel farkındalığının akademik başarının anlamlı yordayıcısı olup olmadığını test etmek için öncelikle korelasyon analizi, sonra da basit doğrusal regresyon analizleri kullanılmış ve korelasyon sonuçları Tablo 7'de, regresyon sonuçları da Tablo 8'de gösterilmiştir.

Tablo 7.

Akademik Başarı ve Üstbilişsel Farkındalık Arasındaki İlişkiye Dair Korelasyon Sonuçları

\begin{tabular}{llll}
\hline & & Üstbiliş Toplam & AGNO \\
\hline Üstbiliş Toplam & Pearson Correlation & 1 & $.102^{* *}$ \\
& $\mathrm{p}$ & & .005 \\
& $\mathrm{~N}$ & 745 & 745 \\
\hline AGNO & Pearson Correlation & $.102^{* *}$ & 1 \\
& $\mathrm{p}$ & .005 & \\
& $\mathrm{~N}$ & 745 & 745 \\
\hline
\end{tabular}

Tablo 7'de sunulduğu üzere akademik başarı ile üstbilişsel farkındalık arasında istatistiksel açıdan anlamlı doğrusal, pozitif ve düşük düzeyde bir ilişki vardır ( $r=.102$, $\mathrm{p}<.01)$.

Basit doğrusal regresyon analizi soncunu, öğretmen adaylarının üstbilişsel farkındalıklarının akademik başarılarının bir yordayıcısı olup olmadığını test eden modelin istatistiksel açıdan anlamlı olduğunu $\left(\mathrm{F}_{(1,743)}=7,882, \mathrm{p}<.05\right)$ göstermektedir.

Tablo 8

Akademik Başarı ve Üstbilişsel Farkındalık Arasındaki İiş̧kiye Dair Regresyon Analizi Sonuçlart

\begin{tabular}{|c|c|c|c|c|c|}
\hline \multirow{2}{*}{ Model } & \multicolumn{2}{|c|}{$\begin{array}{l}\text { Standartlaştırılmamış } \\
\text { katsayılar }\end{array}$} & \multirow{2}{*}{$\begin{array}{l}\text { Standart } \\
\text { katsayılar } \\
\text { Beta }\end{array}$} & \multirow{2}{*}{$\mathrm{t}$} & \multirow{2}{*}{$\mathrm{p}$} \\
\hline & B & Std. Hata & & & \\
\hline (Sabit) & 2.289 & .128 & & 17.939 & .000 \\
\hline üstbiliş toplam & .002 & .001 & .102 & 2.808 & .005 \\
\hline
\end{tabular}

Tablo 8'de sunulduğu üzere öğretmen adaylarının üstbiliş farkındalıkları akademik başarılarının anlamlı bir yordayıcısıdır. Bu durum;

Akademik Başarı $=.002$ Üstbilişsel Farkındalık +2.289 
formülle ifade edilebilir. Son olarak üstbiliş farkındalık akademik başarının toplam varyansının \% 1'ini (=.01) açıklamaktadır.

\section{Sonuç ve Tartışma}

Öğretmen adaylarının üstbilişsel farkındalık düzeyleri; bu düzeylerin bölüm, sınıf düzeyi ve cinsiyet değişkenlerine göre farklılaşıp farklılaşmadığı ve üstbilişsel farkındalıklarının akademik başarılarını yordama durumunun incelendiği bu araştırmada aşağıdaki sonuçlara ulaşılmıştır.

Üstbilişsel farkındalık düzeyleri düşük, orta ve yüksek şeklinde sınıflandırıldığında katılımcıların büyük bir bölümünün yüksek düzeyde farkındalığa sahip olduğu görülmüştür. Düşük düzeyde farkındalık ise yok denecek kadar azdır. Her bir bölüm içerisinde de benzer bir dağılım söz konusudur. Bu sonuca paralel olarak Akın ve diğerleri (2007), Baş, Sağırlı ve Bekdemir (2016), Memnun ve Akkaya (2012), Yavuz (2009) tarafindan yapılan araştırma sonucunda da öğretmen adaylarının üstbiliş farkındalık düzeylerinin genel itibariyle yüksek olduğu ifade edilmiştir.

Öğrenim görülen bölümün katılımcıların farkındalıkları üzerinde etkili olduğu belirlemiştir. Fen bilgisi ve sınıf öğretmenliği anabilim dalında öğrenim görmekte olan katılımcıların farkındalıklarının ilköğretim matematik öğretmenliği anabilim dalında öğrenim görmekte olan katılımcilardan yüksek olduğu bulunmuştur. Memnun ve Akkaya'nın (2012) çalışmasında sınıf öğretmenliği öğrencilerinin üstbilişsel farkındalıklarının fen ve matematik öğrencilerine göre daha yüksek olduğu belirlenmiştir. Alkan ve Erdem (2014)'in çalışmasında ise öğrenim görülen program türünün üstbilişsel farkındalık üzerinde etkili olmadığı tespit edilmiştir.

Bölüm ve sınıf düzeyinin kombinasyonu da farkındalık üzerinde etkili olan diğer bir değişkendir. Birinci sınıf düzeyinde bölümler arasında farklılık yoktur. İkinci ve üçüncü sınıf düzeyinde sınıf öğretmenliği ve fen bilgisi öğretmenliği dördüncü sınıfta ise fen bilgisi ve sosyal bilgiler öğretmenliği anabilim dalında öğrenim gören katılımcıların farkındalıklarının daha yüksek olduğu bulunmuştur. Burada dikkat çekici olan nokta bölümlerin hemen hemen aynı üstbilişsel farkındalık düzeyine sahipken süreç içerisinde farkındalık düzeylerindeki değişimdir. Yapılan bu çalışmada matematik ve sosyal bilgiler öğretmenliği anabilim dalında öğrenim gören katılımcıların ikinci sınıfta üstbilişsel farkındalıkları düşmüştür. İlgili anabilim dallarındaki lisans programlarında bilhassa ilk yıl ilgili alana özgü temel dersler diğer anabilim dallarına kıyasla daha ağırlıklı düzeydedir. Katılımcıların bu alan dersleri ile yoğun bir şekilde karşı karşıya kalması da farkındalık seviyelerindeki değişimle ilişkilendirilebilir. Daha sonra katılımcıların üçüncü ve dördüncü sınıfta farkındalık seviyeleri tekrar yükselmeye başlamıştır. Fen Bilgisi öğretmenliği anabilim dalında öğrenim gören katılımcıların ise üstbilişsel farkındalık düzeyleri sürekli artış göstermiştir. Bu beklenen bir sonuçtur denilebilir. Çünkü eğitim fakültelerinde yer alan programlarda yer alan eğitim dersleri son sınıfa doğru ağırlık göstermektedir. $\mathrm{Bu}$ 
dersler de yapısı itibariyle neden, niçin şeklindeki sorgulamalara ve yansıtıcı düşünme firsatlarına imkân tanıyan derslerdir ve üstbilişsel stratejilerin kullanımı, üstbilişsel stratejilerin öğretimi gibi bazı öğretim yöntemleri yardımıyla bireye kazandırılabilir (Kramarski \& Hirsch, 2003). Dolayısıyla katılımcıların aldıkları dersler, üstbilişsel farkındalık düzeylerini arttırmış olabilir. Ancak çalışmada beklenmeyen bir sonuç diyebileceğimiz bir nokta ise sınıf öğretmenliği anabilim dalında öğrenim gören katılımcıların ikinci ve üçüncü sınıfta üstbilişsel farkındalık düzeylerinin yüksek olmasına rağmen son sınıfta üstbilişsel farkındalık düzeylerinin ciddi bir düşüş yaşamasıdır. $\mathrm{Bu}$ durum yine lisans programlarında yer alan eğitim derslerindeki geçişlerin bir sonucu olarak düşünülebilir. Fakat 2018-2019 öğretim yılı itibariyle yeni lisans programlarının uygulamaya girmesi bu sonuç üzerinde bir değişiklik yapabileceğinden ilgili konu tekrar incelemeye tabi tutulabilir.

Literatürde özellikle sınıf seviyesini dikkate alan çalışmalar mevcuttur. $\mathrm{Bu}$ çalışmalardan bir kısmında sınıf düzeyi üstbilişsel farkındalık açısından anlamlı bir fark oluşturmamıştır (Baykara, 2011; Deniz ve diğerleri, 2014; Gül, Köse \&Yılmaz, 2015; Kana, 2015). Sınıf düzeyi değişkeni Özsoy ve Günindi’nin (2011) çalışmasında ikinci ve dördüncü sınıflar arasında, dördüncü sınıflar lehine; Memnun ve Akkaya (2012)'nın çalışmasında üçlerin ve dörtlerin birlere ve ikilere göre daha yüksek; Belet ve Güven (2011)'in çalışmasında da farklı alt boyutlarda farklı sınıf seviyelerinin lehine anlamlı fark oluşturduğu görülmüştür.

Cinsiyet ve sınıf düzeyi ile belirlenen değişkenlerin bölüm*cinsiyet, sınıf düzeyi*cinsiyet, bölüm*sınıf düzeyi*cinsiyet şeklindeki kombinasyonlarının katılımcıların üstbilişsel farkındalıkları üzerinde etkili olmadığı görülmüştür. Yalnızca cinsiyetin ele alındığı Deniz ve diğerleri, (2014), Gül, Köse ve Yılmaz (2015), Özsoy ve Günindi (2011), Sarwar ve diğerleri (2009) tarafindan yapılan araştırmalarda cinsiyet öğretmen adaylarının üstbilişsel farkındalıkları üzerinde yapılan bu araştırmaya paralel olarak anlamlı bir farklılık oluşturmazken Bağçeci vd (2011), Baykara (2011), Belet ve Güven (2011), Demir (2013) ve Kana (2015) tarafından yapılan araştırmalarda ise kızların lehine anlamlı bir farklılığın olduğu tespit edilmiştir.

Çalışmada elde edilen bir diğer sonuç ise akademik başarı ve üstbilişsel farkındalık arasında pozitif ve zayıf düzeyde bir ilişki olduğudur. Ayrıca üstbilişsel farkındalık akademik başarının anlamlı bir yordayıcısı olup toplam varyansın \%1'ini anlamlı olarak açıkladığı tespit edilmiştir. Literatürde de bu sonuçla eşleşen benzer çalışmalar mevcuttur. Bağçeci ve diğerleri (2011) ve Kaya ve Fırat (2011) 5, 6 ve 7. sınıf öğrencilerinin üstbiliş puanları ile akademik başarıları arasında anlamlı ancak zayıf bir ilişki tespit etmişlerdir. Belet ve Güven (2011), Cautinho (2007), Romainville (1994), Tok, Özgan ve Döş’ün (2010) çalışmalarında da akademik başarı ile üstbilişsel farkındalık arasında anlamlı bir ilişki tespit edilmiştir. Ancak Ergül (2004) ve Sarwar ve diğerleri (2009) yaptıkları çalışma sonucunda akademik başarı ve üstbiliş arasında bir ilişkiye rastlamamıştır. 


\section{Çıkar Çatışması ve Etik Bildirimi}

Yazarlar aralarında çıkar çatışması bulunmadığını ve tüm araştırmacıların çalışmaya katkı sunduğunu beyan etmiştir. Yazarlar tüm etik kurallara uyduklarını bildirmiştir.

\section{Kaynakça}

Akın, A., Abacı, R., \& Çetin, B. (2007). The validity and reliability of the Turkish version of the metacognitive awareness inventory. Educational Sciences: Theory \& Practice, 7(2), 671-678.

Alkan, F., \& Erdem, E. (2014). The relationship between metacognitive awareness, teacher selfefficacy and chemistry competency perceptions. Procedia-Social and Behavioral Sciences, $143,778-783$.

Altındağ M. (2008). Hacettepe üniversitesi eğitim fakültesi öğrencilerinin yürütücü biliş becerileri (Yayımlanmamış doktora tezi). Hacettepe Üniversitesi Sosyal Bilimler Enstitüsü, Ankara.

Bağçeci, B., Döş, B., \& Sarıca, R. (2011). İlköğretim öğrencilerinin üstbilişsel farkındalık düzeyleri ile akademik başarısı arasındaki ilişkinin incelenmesi. Mustafa Kemal Üniversitesi Sosyal Bilimler Enstitüsü Dergisi, 8(16), 551-566.

Baş, F., Sağırlı, M. Ö., \& Bekdemir, M. (2016). Ortaokul matematik öğretmen adaylarının üstbiliş farkındalıkları, problem çözmeye yönelik inançları, tutumları ve aralarındaki ilişki. Eğitimde Kuram ve Uygulama, 12(2), 464-482.

Baykara, K. (2011). Öğretmen adaylarının bilişötesi öğrenme stratejileri ile öğretmen yeterlik algıları üzerine bir çalışma. Hacettepe Üniversitesi Eğitim Fakültesi Dergisi, 40, 80-92.

Baysal, Z. N., Ayvaz, A., Çekirdekçi, S., \& Malbeleği, F. (2013). Sınıf öğretmeni adaylarının üstbilişsel farkındalıklarının farklı değişkenler açısından incelenmesi. Marmara Üniversitesi Atatürk Ĕgitim Fakültesi Ĕ̈itim Bilimleri Dergisi, 37, 68-81.

Belet, S. D., \& Güven, M. (2011). Meta-cognitive strategy usage and epistemological beliefs of primary school teacher trainees. Educational Sciences: Theory and Practice, 11(1), 5157.

Bendixen, L. D., \& Hartley, K. (2003). Successful learning with hypermedia: The role of epistemological beliefs and metacognitive awareness. Journal of Educational Computing Research, 28(1), 15-30.

Cautinho, S. A. (2007). The relationship between goals, metacognition and academic success. Educate , 7(1), 39-47.

Cartwright Hatton, S., \& Wells, A. (1997). Beliefs about worry and intrusions: The MetaCognitions Questionnaire and its correlates. Journal of Anxiety Disorders, 11(3), 279-296. 
DeCarlo, L. T. (1997). On the meaning and use of kurtosis. Psychological Methods, 2(3), $292-$ 307.

Demir, Ö. (2013). A validation and reliability study of the metacognition scale in Turkey. Global Journal of Human Social Science Linguistics \& Education, 13(10), 27-35.

Demir, Ö., \& Kaya, H. İ. (2015). Öğretmen adaylarının bilişsel farkındalık beceri düzeylerinin eleştirel düşünme durumları ile ilişkilerinin incelenmesi. Pegem Ĕ̆itim ve Öğretim Dergisi, 5(1), 35-68.

Deniz, D., Küçük, B., Cansız, Ş., Akgün, L., \& İşleyen, T. (2014). Ortaöğretim matematik öğretmeni adaylarının üstbiliş farkındalıklarının bazı değişkenler açısından incelenmesi. Kastamonu Ĕ̈itim Dergisi, 22(1), 305-320.

Desoete, A. (2009). Metacognitive prediction and evaluation skills and mathematical learning in third-grade students. Educational Research and Evaluation, 15(5), 435-446.

Desoete, A., \& Veenman, M. V. J. (2006). Metacognition in mathematics education. Hauppauge/ New York: Nova Science Publishers.

Efklides, A. (2006). Metacognition and affect: What can metacognitive experiences tell us about the learning process? Educational Research Review, 1(1), 3-14.

Efklides, A. (2009). The role of metacognitive experiences in the learning process. Psicothema, 21(1), 76-82.

Ergül, H. (2004). Relationship between student characteristics and academic achievement in distance education and application on students of Anadolu University. Turkish Online Journal of Distance Education, 5(2), 81-90.

Flavell, J. H. (1979). Metacognition and cognitive monitoring: A new area of cognitivedevelopmental inquiry. American Psychologist, 34(10), 906.

Fraenkel, J. R., \& Wallen, N. E. (2006). How to design and evaluate research in education. New York: Mc Grawall Hill.

Garofalo, J., \& Lester Jr, F. K. (1985). Metacognition, cognitive monitoring, and mathematical performance. Journal for Research in Mathematics Education, 16(3), 163-176.

Gül, Ş., Köse, E. Ö., \& Yılmaz, S. S. (2014). Biyoloji öğretmeni adaylarının üstbiliş farkındalıklarının farklı değişkenler açısından incelenmesi. Hasan Âli Yücel Eğitim Fakültesi Dergisi, 12-1(23), 83-91.

Kana, F. (2015). Türkçe öğretmeni adaylarının motivasyonel, bilişsel ve bilişüstü yeterlikleri. Uluslararası Ĕ̈itim Bilimleri Dergisi, 2(4), 395-407.

Karakelle, S. (2012). Üstbilişsel farkındalık, zekâ, problem çözme algısı ve düşünme ihtiyacı arasındaki bağlantılar. Ĕgitim ve Bilim, 37(164), 237-248. 
Kaya, N. B., \& Firat, T. (2011). İlköğretim 5. ve 6. sınıf öğrencilerinin öğrenme-öğretme sürecinde üstbilişsel davranışların incelenmesi. Celal Bayar Üniversitesi Eğitim Fakültesi Dergisi, 1(1), 57-71.

Kayri, M. (2009). Araştırmalarda gruplar arası farkın belirlenmesine yönelik çoklu karşılaştırma (post-hoc) teknikleri. Journal of Social Science, 19(1), 51-64.

Kiremitçi, O. (2011). Beden eğitimi öğretmen adaylarının üstbilişsel farkındalık ve problem çözme becerileri arasındaki ilişkinin incelenmesi. Selçuk Üniversitesi Beden Eğitimi ve Spor Bilim Dergisi, 13(1), 92-99.

Kramarski, B., \& Hirsch, C. (2003). Effect of computer algebra system (CAS) with metacognitive training on mathematical reasoning. Icem-Cime Annual Conference, Granada. Educational Media International, 40(3-4), 249-257.

Kroll, D. L., \& Miller, T. (1993). Insights from research on mathematical problem solving in he middle grade. In D. Owens (Ed.) Research ideas for the classroom: Middle grade mathematics (pp. 8-27). Reston, VA: NCTM.

Lance, C. E., Butts, M. M., \& Michels, L. C. (2006). The sources of four commonly reported cutoff criteria: What did they really say? Organizational Research Methods, 9(2), 202-220.

Marcus, A. (2007). Coding strategic behavior in mathematical problem solving. In D. Kuechemann (Ed.), Proceedings of the British Society for Research into Learning Mathematics, 27, 54-59.

Martinez, M. E. (2006). What is metacognition? Phi Delta Kappan, 87(9), 696-699.

Memnun, D. S., \& Akkaya, R. (2012). Matematik, fen ve sınıf öğretmenliği öğrencilerinin bilişötesi farkındalıklarının bilişin bilgisi ve düzenlenmesi boyutları açısından incelenmesi. Kuramsal Eğitimbilim Dergisi, 5(3), 312-329.

Namlu, A. G. (2004). Bilişötesi öğrenme stratejileri ölçme aracının geliştirilmesi: geçerlilik ve güvenirlik çalışması. Anadolu Üniversitesi Sosyal Bilimler Dergisi, 4(2), 123-136.

Özsoy, G., \& Günindi, Y. (2011). Okulöncesi öğretmen adaylarının üstbilişsel farkındalık düzeyleri. İlköğretim Online Dergisi, 10(2), 430-440.

Romainville, M. (1994). Awareness of cognitive strategies: The relationship between university students' metacognition and their performance. Studies in Higher Education, 19(3), 359366.

Sarpkaya, G., Arık, G., \& Kaplan, H. A. (2011). İlköğretim matematik öğretmen adaylarının üstbiliş stratejilerini kullanma farkındalıkları ile matematiğe karşı tutumları arasındaki ilişki. Sosyal Bilimler Araştırmaları Dergisi, 2, 107-122.

Sarwar, M., Yousuf, M., I, Hussain S., \& Noreen S. (2009). Relationship between achievement goals, meta-cognition and academic success in Pakistan. Journal of College Teaching \& Learning, 6(5), 51-56. 
Schraw, G., \& Dennison, R. S. (1994). Assessing metacognitive awareness. Contemporary Educational Psychology, 19(4), 460-475.

Sheorey, R., \& Mokhtari, K. (2001). Differences in the metacognitive awareness of reading strategies among native and non-native readers. System, 29(4), 431-449.

Sökmen, Y., \& Kılıç, D. (2016). Sınıf öğretmeni adaylarının yürütücü biliş, düşünme stilleri ve akademik başarı arasındaki ilişki. Kastamonu Eğitim Dergisi, 24(3), 755-772.

Tok, H., Özgan, H., \& Döş, B. (2010). Assessing metacognitive awareness and learning strategies as positive predictors for success in a distance learning class/uzaktan eğitim sınıfında başarının pozitif yordayıcısı olarak bilişötesi farkındalık stratejisi ve öğrenme stratejilerinin değerlendirilmesi. Mustafa Kemal Üniversitesi Sosyal Bilimler Enstitüsü Dergisi, 7(14), 123-134.

Tosun, A., \& Irak, M. (2008). Üstbiliş Ölçeği-30’un Türkçe Uyarlaması, Geçerliği, Güvenirliği, Kaygı ve Obsesif-Kompülsif Belirtilerle İlişkisi. Türk Psikiyatri Dergisi, 19(1), 7-80.

Vandergrift, L. (2005). Relationships among motivation orientations, metacognitive awareness and proficiency in L2 listening. Applied linguistics, 26(1), 70-89.

Van der Stel, M., \& Veenman, M. V. (2010). Development of metacognitive skillfulness: A longitudinal study. Learning and individual differences, 20(3), 220-224.

Veenman, M. V. J. (2005). The assessment of metacognitive skills: What can be learned from multi-method designs? In C. Artelt \& B. Moschner (Eds.), Lernstrategien und Metakognition: Implikationen für Forschung und Praxis (pp. 75-97). Berlin: Waxmann.

Veenman, M. V. J. (2006). The role of intellectual and metacognitive skills in math problemsolving. In A. Desoete \& M. V. J. Veenman (Eds.), Metacognition in mathematics education (pp. 35-50). New York: Nova Science Publishers.

Veenman, M. V., Van Hout-Wolters, B. H., \& Afflerbach, P. (2006). Metacognition and learning: Conceptual and methodological considerations. Metacognition and Learning, $1(1), 3-14$.

Yavuz, D. (2009). Öğretmen adaylarının öz-yeterlik algıları ve üstbilişsel farkındalıklarının çeşitli değişkenler açısından incelenmesi (Yayımlanmamış yüksek lisans tezi). Zonguldak Karaelmas Üniversitesi Sosyal Bilimler Enstitüsü, Zonguldak.

Wilson, J. (1999). The Nature of Metacognition: What do primary school problem solvers do? In D. Barwood, D. Greaves, \& P. Jeffery (Eds.), Teaching numeracy and literacy: Interventions and strategies for "at risk" students (pp. 283-294). Coldstream, Victoria: Australian Resource Educators' Association.

Yang, C. T., \& Lee, S. Y. (2013). The effect of instruction in cognitive and metacognitive strategies on ninth-grade students' metacognitive abilities. New Waves-Educational Research \& Development, 16(1), 46-55. 


\section{Extended Abstract}

The metacognition was first defined by Flavell (1979) as “individuals' knowledge about their cognitive processes and their using of this knowledge to manage these cognitive processes". Unlike the cognition, metacognition consists of using various decision-making processes, various observation and choosing strategies (Marcus, 2007; Martinez, 2006; Veenman et al., 2006; Yang \& Lee, 2013). Studies, referring that the metacognition has a key role as a variable in estimation of the learning products, also exist (Desoete 2009; Desoete \& Veenman, 2006). Moreover, to express in numbers, metacognition measured during a learning task can explain that learning variance up to $37 \%$ (Veenman et al., 2006). The metacognition is associated not only with the learning results as a product, but also with the variables as problem solving skill, intelligence and academic achievement. For instance, it was referred that $43 \%$ of the variability at the level of the metacognitive awareness could explained with the significant contributions by the perception of solving personal problems, need of thinking and intelligence (Karakelle, 2012). In addition, it is realised that the studies related to determine the variables (class level, studied department, gender, school type, living area, parents education level etc.) which can be effective on the metacognition, existed in a wide range of field.

In order to present a holistic picture, it was aimed to investigate the metacognitive awareness levels of the pre-service teachers, whether these levels demonstrate differences or not in terms of the department, class level and gender variables and the case of metacognitive awareness predicting their academic achievements in this research.

The sampling of the study consisted of totally 764 participants, who were under education of the departments of Secondary School Mathematics Teaching, Primary School Teaching, Science and Social Studies Teaching in the Faculty of Education in a medium scale province of the Eastern Anatolia Region of Turkey in 2015-2016 educational year.

Three different data were collected in the research as the demographic characteristics of the participants (department, which the participants studies at, class level and gender), academic achievements (undergraduate general achievement average) and their metacognitive awareness levels. To determine the demographic characteristics and academic achievements of the participants, a form was prepared by the researchers. The data related to the metacognitive awareness of the participants were collected with the Metacognitive Awareness Inventory (MAI), which was developed by Schraw and Dennison (1994) and translated into Turkish by Akın et al. (2007), in 5-point Likert type and validity and reliability applications were checked. For the whole of the inventory, the Cronbach's Alpha reliability coefficient was calculated by Schraw and Dennison (1994) as =.95; by Akın et al. (2007) as =.95; and in this research as $=.938$. It is submitted to the participants to be filled in classroom 
environment after the necessary permissions. In data analysis process, the descriptive statistics, multi-factored ANOVA and simple linear regression test were used.

As the metacognitive awareness levels were classified as low, medium and high, it was noticed that a large number of the participants had high level of awareness. The low level of awareness was almost none.

The study department was determined to be effective on the awareness of the participants. It was found that the awareness of the participants from the science and primary school teacher training departments had higher levels of awareness compared with the participants secondary school mathematics teacher training department.

The combination of department and class level was another variable that affected the awareness. No difference occurred among the departments at the first class level. It was found that the participants from second and third class levels of the primary school teacher training and science teacher training departments and science and social studies teacher training departments in fourth-class level were determined to have high awareness. The remarkable point here is that while the departments have almost the same level of metacognitive awareness, the change occurrence in their awareness levels through the process.

In this study, it was also found that the metacognitive awareness of the participants from the secondary school mathematics and social studies teacher training departments decreased at the second class. In undergraduate programs of the relevant departments, the field courses first year are more dominant compared with the other departments. Intensive confrontation of participants with these field courses can also be associated with the changes in awareness levels.

Then, the awareness levels of the participants increased again at the third and fourth classes. The metacognitive awareness levels of the participants in science teaching department were continuously increased. This can be referred as an expected result. Because, the teaching courses at the departments of the faculty of education demonstrate an increasing dominance through the fourth classes. These are the courses, which enable to interrogate and reflective thinking opportunities with their nature and can be gained by individuals with some teaching methods using the metacognitive strategies and teaching metacognitive strategies (Kramarski \& Hirsch, 2003). Therefore, the courses given to the participants may increase their metacognitive awareness levels. However, a point, which can be expressed as an unexpected result was that although the metacognitive awareness levels of the participants from primary school teacher training department were high at the second and third classes, they had significant decrease in their metacognitive levels in the fourth class. This case can even be thought as a result of the transitions occurred in teaching courses stated in the undergraduate programs. However, the relevant topic can be handled again as the new undergraduate programs will be applied from 20182019 educational year. 
It was observed that the combinations as department*gender, class level*gender, department*class level*gender were found to have no effect on the metacognitive awareness of the participants as the gender variable.

Another result gathered from the study was that the positive and weak level of relationship between the academic achievement and metacognitive awareness. In addition, it was determined that the metacognitive awareness was the significant predictor of the academic achievement and it explained $1 \%$ of the total variance meaningfully. 